\title{
Tourism Based on the Model of Strategic Place Triangle (A Case Study in Wisata Bahari Lamongan)
}

\author{
Ismuhadi Heru Wijayanto ${ }^{1}$, M. Saleh Soeaidy ${ }^{2}$, Siti Rochmah ${ }^{3}$ \\ ${ }^{1}$ Master Program of Public Administrative, Faculty of Administrative Sciences, University of Brawijaya, Malang \\ ${ }^{2}$ Faculty of Administratives Sciences, University of Brawijaya, Malang
}

\begin{abstract}
Tourism is a very promising prospects to support the economic development of a region. We assess Wisata Bahari Lamongan (WBL) as a tourism object. WBL was having significant decreased visitors in the last six years, thus a strategic plan is need to re-increase the number of visitors. This study used Strategic Triangle Place (SPT) model as an analysis tool to assess the strategic planning in WBL. SPT is an approach that includes three key components, namely: Positioning, Differentiation and Brand (PDB). This research used Soft System Methodology (SSM) which relevant to analyze the strategic plan model which is expected to be recommendations from tourists on problems in WBL. The result of this showed that the strategic planning of WBL did not completely accordance with the SPT model. Positioning and differentiation elements were still weak, and the brand was not well developed. Therefore, we recommend WBL to set targeted segmentation of all social backgrounds and ages, especially children. WBL should made the sea as main differentiated factor, thus it has marine tourism potential. WBL should build an image by providing best service quality, security, comfortness, cleanliness, and best quality rides.
\end{abstract}

Keywords: PDB, Strategic Place Triangle, WBL.

\section{INTRODUCTION}

Tourism has grew and become one of the largest and fastest growth economic sectors in the world. In 2009, the contribution of tourism to the worldwide economic activity is estimated about 5\% [1]. Because of that, currently many countries should take advantage from the tourism sector as a focus of future economic progress, including Indonesia. Because Indonesia already has sufficient capital value, i.e. great natural potencies to establish the strategic tourism areas.

Wisata Bahari Lamongan (WBL) was a marine tourism built in Lamongan in 2004. It is restructured and developed with cooperation between Lamongan Government and PT. Bunga Wangsa Sejati. Since it built in 2004, WBL has great contribution to the local revenue (PAD). Therefore WBL become the leading tourism product for Lamongan [2].

In the first year, WBL successfully get a total profit of 9 billion from a target of 7.5 billion, thus the next year target was raised to 9 billion. But, over the development of global tourism, the local revenue ratio in the last few years was bad due to the decreased visitor numbers.

\footnotetext{
* Correspondence address:

Ismuhadi Heru Wijayanto

Email : heru.wijaya91@gmail.com

Address : Master Program of Public Administrative, Faculty of Administrative Science, Malang 65145
}

Considered on these orientations, then in this study try to put forward a planning strategy based on the Strategic Place Triangle (SPT) perspective. Through this strategic planning, we absolutely necessary to reconsidering the role of WBL as a Lamongan Regency main attraction for tourism. Moreover, tourism visitors were decreased for the last six years in WBL. SPT is an approach of marketing places that includes three key components namely: Positioning, Differentiation and Brand [3].

SPT approach was taken because of successful experienced of Bali and Yogyakarta. The objectives of this study are to assess, describe, and analyze the Wisata Bahari Lamongan strategic planning based on SPT model.

\section{Strategic Place Triangle}

This study used a main theory namely Strategic Place Triangle (Fig. 1). SPT has three key components as follows:

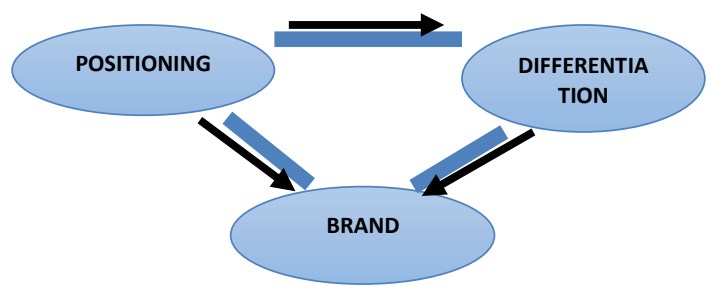

Figure 1. Strategic Place Triangle Model [3] 


\section{Positioning}

The aim of positioning is to establish the funding firm's trustworthiness, confidence, and competence for investors (credibility). The company must define its identity and personality in the investor's mind [4].

As we move more into the era of globalized markets, where capital flow freely anywhere to obtain the best returns, companies should no longer depend on their traditional investors to provide financing when it is needed. Creditors no longer manage their investors; their investors have to be the lead. Leading takes credibility. Positioning is not just about persuading. It is also about earning investors' trust and confidence [4].

\section{Differentiation}

Differentiation is a crucial factor for the success in attracting company funding. The essence of strategic differentiation is to choose activities that different from the rivals. A company's sustainable competitive advantage will be developed through the strategic fit between the various activities that make up this unique position. Thus, that positioning and differentiation are the key to achieve competitive advantage. Both form the essence of a company's strategy and tactics. Positioning is the core of the strategy, while differentiation is the core of the tactics [4].

\section{Brand}

Brand is not solely developed through commercials in the mass media. More importantly, it can be developed through applying the right strategies, tactics, and value. Brand is not simply a name, logo, or symbol; nor is it merely the representation of company's products or services.

In the context of marketing the capital market, brand is the canopy that represents a company as a whole-brand; in this sense is more closely related to corporate brand. It is a reflection of a company reputation-value given and/or promised to the investors. Hence, it is generally taken as a company's value indicator [4].

\section{MATERIALS AND METHODS}

This study take place at Lamongan Regency and Wisata Bahari Lamongan (WBL) as a research object. We review the SPT models as a reference for the tourism strategic planning in Wisata Bahari Lamongan. This research used Soft System Methodology (SSM) to analysis the strategic plan model to solve the tourism problem in Lamongan
Regency, especially Wisata Bahari Lamongan. SSM provide an explicit, organized and defensible way of reconciling different and/or conflicting perspectives. It means to build a model of business processes that appropriate to the users within the concern area. In addition, the useful of this model according to Wilson [5] are as follows:

1. Compare the reality to make recommendations for procedural change which can be argued to be beneficial.

2. Form a single model, reconciling many perspectives, representing description of a proposed business area.

3. Compare the model towards reality to redefine the roles and organizational structures.

4. Use the model as a source of information requirements to support the business area.

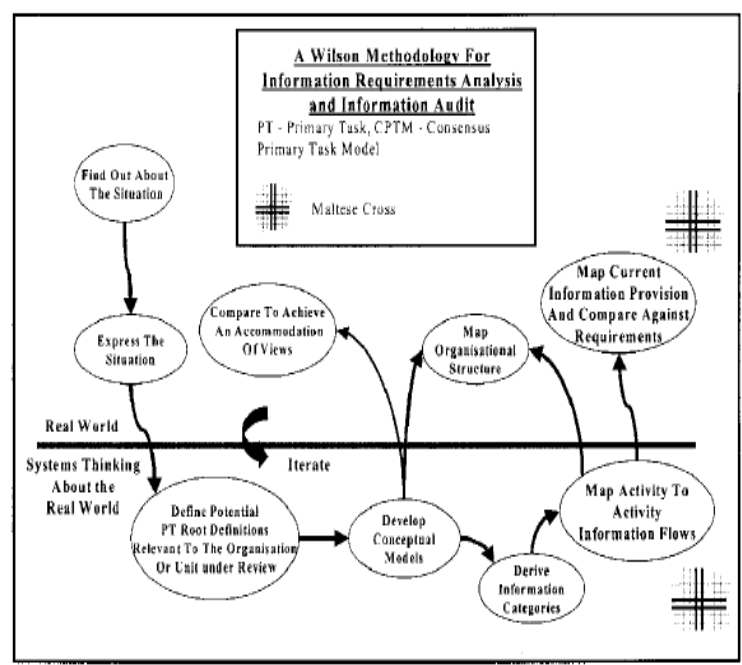

Figure 2. Wilson Methodology [5]

\section{RESULTS AND DISCUSSION}

In this study we found that the decreased visitors were problem in WBL. By using the SSM method, we describe the situation in the real world and determine the root of problems (Fig. 3).

The problems of declining visits to WBL were caused by mullti-actor and multi-instrumental aspects. Lamongan Government and private entrepreneurs were key actors in the development of WBL. In fact, they were not well integrated. Private company was lack of transparency related to the financial statements of WBL. The government also has weak control to the private sector performance. These problems was the dominant issue in the dimension of actor.

The aspects that influence the development of WBL was also quite complex, includes natural, 
cultural, and strategic planning. In terms of nature and culture, a factor that became the main obstacles was the rain and hot weather in the WBL. Rain cause the whole operation of outdoor game to be stopped considering the safety. This situation could lead to the disappointment of visitors. The hot weather had been also affecting the comfort of visitors. The state of nature and culture was normal thing, but a practical solution was needed by the WBL.

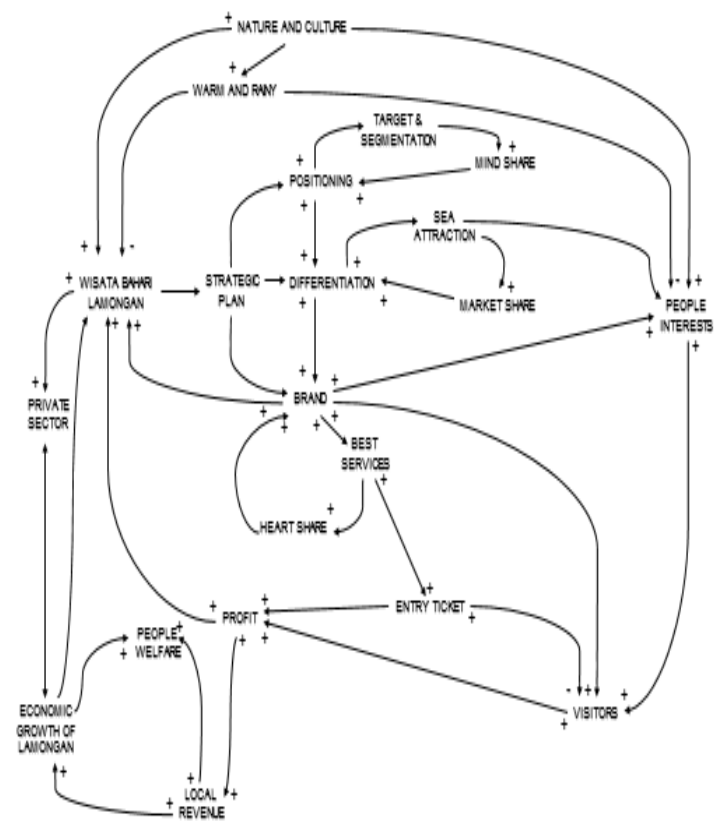

Figure 3. Mapping of Problems' Root

Strategic planning was one of the main aspects to encourage a better development of WBL. Due to the absence of a good strategic plan, WBL had been not create any sustainable development. This argument was in accordance with Wilson [5] that explained the strategic planning as a tool for organizing the existence of the basis projections in the expected future. A strategic plan was a road map to lead an organization from present time and their vision to be in five or ten years later. Thus, an organization needs to have their strategic plan.

In strategic planning, the mission to be achieved in the future should also be clear. Therefore, an urgent mission must have a systematic written plan. Because no systematic mission make the achievement of the goals difficult. In the context of WBL, the weakness was the systematic mission to overcome the problems of declining visitors. Strategic planning was an essential process in preparing to carry out your organization's mission. An effective strategic planning process provides a framework to make decisions on how to allocate organizational resources, address challenges and take advantage of opportunities that arise along the way.

Furthermore, in this study researcher have been used a model of Strategic Place Triangle (STP), as a comparison between the real world with the model used. We found that brand is a key element of the existing problems of strategic planning in WBL. Because the brand has a tremendous influence, then the weak brand will automatically affect the visitor level and people interest towards the WBL itself.

\section{Determination of Positioning}

In the context of WBL development, positioning was determined whether the WBL aspects could have a special place in the perception of the visitors. Furthermore, analysis on the related positioning had been based on six elements (Table 1 ).

Table 1. Alternatives Strategy of Positioning in WBL

\begin{tabular}{ll}
\hline $\begin{array}{c}\text { Positioning } \\
\text { Element }\end{array}$ & \multicolumn{1}{c}{ Strategy } \\
\hline tourism attributes & $\begin{array}{l}\text { WBL should always perform } \\
\text { maintenance on rides' games and } \\
\text { additions binually. }\end{array}$ \\
provided benefits & $\begin{array}{l}\text { WBL should reinforce the image that } \\
\text { WBL rides are safe, comfortable, and } \\
\end{array}$ \\
& fun to spend the holidays.
\end{tabular}

use of events

WBL should improve the quality of care during holidays, because during the holidays, the visits was highlevel.

specific user class WBL should reinforce the image dedicated for all classes, especially the lower middle class.

direct comparison WBL should strengthen the maritime to competitors superiority compared to other tourism that have the same concept

different classes WBL should intensify the promotion of tourism of affordable tourism.

activities

WBL was already well positioned. The next activity after determine the positioning is communication to all stakeholders as the marketting target of WBL. Stakeholders comprise of visitors, employees, and shareholders (government and private). The important thing to remember that positioning could also communicate through the offered price of admission, game rides, provided services, 
time series differentiation and constructed or developed through the process in delivering value to the visitor.

The statements were relevant to Kotler [4] opined that competitor assessment that holds a company's positioning should be unique and easily differentiated from its competitors. Determination of the strong differentiation give a unique value for WBL compared to other tourism. Thus the competitiveness of WBL had been high. Effective communication in positioning aspects are as follows:

- Creative; Creative communicating attempted to steal positioning in the minds and attention of visitors. It must be remembered that WBL compete with hundreds of other tourism to get into the minds of visitors.

- Simplicity; Communication in positioning should be done as simple as possible and as clearly as possible thus visitors do not get confused captures the essence of positioning. Internal positioning may be complicated, but towards visitors, WBL should also ask the visitors thought.

- Own, dominate, protect; The ultimate goal of positioning was how tourism has one or more words that can be entered into the minds of visitors. When tourism has the words, then the next dominant position should be protected from competitors.

- Use their own language; Use simple language to communicate positioning for visitors. It means that WBL was positioned to the village, and then adjust the language with the villagers. Otherwise, if WBL positioned to the top, then use a more elite language.

For WBL, positioning was essentially embed a perception, identity and personality in the minds of visitors. Good positioning of tourism should always be consistent, because the changing created confusion for visitors, thus tourism had been loss of focus. Changes can only be made to suit the needs of visitors and the environment.

The above statements were relevant to Kotler [4] opinion on necessary change in company's positioning relevant to the conditions of business environment. In this case, WBL should manage the market positioning, both segment and target.

\section{Strengthen the Differentiation}

In the context of WBL, the data showed that the primary differentiation aspect of WBL was it location near the sea; as stated earlier that the most powerful of differentiation comes from the unique nature of tourism. Thus WBL has had a very strong capital to develop the differentiation factor, i.e. the beauty of the sea. To create this strong differentiation, WBL should concentrate on three very important things:

Content (what to offer); The "what" value was WBL offer to visitors. Thus WBL differentiate itself from competitors based on "what" WBL offer to visitors.

Context (how to offer); The "way" WBL offer their value to the visitor. WBL must differentiate themselves from competitors based on the "how" WBL offer the value to the visitor.

Infrastructure (enabler); The factors that support the implementation of the content and context of differentiation. In short, the infrastructure was all the things that WBL have and can make a difference "what" the WBL offer and "how" WBL offers to visitors.

Kotler [4] also opined that differentiation was defined as designing a set of meaningful differences in a company's offers. This definition was still valid. But we propose to go further, defining differentiation as integrating the content (what to offer), context (how to offer it), and infrastructure (the enabler) of our offers to visitors. Furthermore, this study analyzed the relation to the three key elements that had been strengthen the tourism differentiation (Table 2).

Table 2. Analysis to Strengthening Differentiation in WBL

\begin{tabular}{|c|c|}
\hline $\begin{array}{c}\text { Differentiation } \\
\text { Element }\end{array}$ & Strategy \\
\hline Content & $\begin{array}{l}\text { The beauty of the beach should be } \\
\text { highlighted in the aspect of } \\
\text { differentiation. }\end{array}$ \\
\hline Context & $\begin{array}{l}\text { WBL should add game rides that } \\
\text { explore the beauty of the sea. E.g. } \\
\text { banana boats and canoes. } \\
\text { Accelerating the development of sea } \\
\text { world will significantly add } \\
\text { competitiveness to WBL. }\end{array}$ \\
\hline Infrastructure & $\begin{array}{l}\text { Package of tours shoul be integrated } \\
\text { with Maharani zoo and cave as } \\
\text { actual opportunity. Furthermore, the } \\
\text { access road to the WBL should be } \\
\text { repaired to improve the quality of } \\
\text { comfort and service, especially } \\
\text { during the holidays. }\end{array}$ \\
\hline
\end{tabular}

WBL has a very valuable capital to determine the differentiation, because WBL located near the sea. The scarcity of the rides game concept near the sea becomes a great opportunity to expand. The rides addition explore the beauty of 
the sea to be the main attraction for visitors interest.

The discourse of sea world development in WBL had been become its own power for WBL because sea world that located in the seaside area are rare. So the discourse was believed to be a differentiated factor for the remarkable increase tourists to visit the WBL.

Kotler [4] explained according to the proper integration of differentiation, content, context, and infrastructure was required to ensure the sustainability. These dimensions must compatible and interact to create the unique values to become the basis of the company's competitive strength. Reviewing on this statement, then seaworld could strengthen the differentiation of WBL for creating unique characteristic.

\section{Brand Building}

In the context of WBL, the determination of a true brand with the efforts done by management to provide the best service quality, security, comfort, and satisfaction in playing the rides. But this could not be called a true brand because the facilities are reasonable demands for all visitors.

Brand was used to win the heart share of the visitors. A brand must have a strong character and a promise to visitors to keep. WBL achieve this goal by providing the best quality of service, safety, comfort, cleanliness and game. In addition, the efforts of WBL brand development also need to highlight the beauty aspects of the sea, due to its called as marine tourism. However, so far WBL seems not to have high brand strength, particular-ly due to the realization of sea world.

Hence, brand was generally taken as a company's value indicator. From this statement, sea world could be the brand of WBL as a great value indicator.

Furthermore, in the subsequent analysis, a brand that was built by WBL had been attempted to be corrected with the meaning of the brand itself. A brand was a name, term, sign, symbol, design, or a combination of all of these were intended to recognize the tourism of the manager that was used to distinguish it from other competitors tourism. So the brand can identify the characteristics of tourism built by the manager. Brand was also the promise of tourism operators to consistently deliver conclusions from nature, benefits, and specific services to visitors.
The analysis related to the development of a brand that has been done by the management of WBL as follows (Table 3).

Table 3. Analysis of Brand Development in WBL

\begin{tabular}{l|l}
\hline \multicolumn{1}{c|}{ Brand Element } & \multicolumn{1}{c}{ Strategy } \\
\hline Attributes & $\begin{array}{l}\text { WBL should utilize as much as } \\
\text { possible the character of the sea to } \\
\text { build a strong brand, such as the } \\
\text { accelerated development of sea } \\
\text { world. Because to date, it has not } \\
\text { been consistent and has particularly } \\
\text { focus on exploring the beauty of the } \\
\text { sea. }\end{array}$ \\
Benefits & $\begin{array}{l}\text { WBL must keep improving and } \\
\text { adding rides games so that visitors } \\
\text { feel satisfied. } \\
\text { WBL has a sustainable good level of } \\
\text { service quality, cleanliness, safety, } \\
\text { and comfort. } \\
\text { Personality }\end{array}$ \\
$\begin{array}{l}\text { WBL should begin to identify } \\
\text { themselves with the characteristic } \\
\text { beauty of the sea due to tremendous } \\
\text { potential of ocean's characteristic in } \\
\text { the future. }\end{array}$ \\
\hline
\end{tabular}

There were still weaknesses of WBL for the determination of the brand. So far the brand that was built by the WBL provide good quality of service, security, cleanliness, comfortness, and rides games. These aspects are an obligation for the management and the general rights that acquired by visitors. In fact, WBL has potential branding to be strengthened, i.e. beauty of the sea. WBL was located near the sea, however it has not optimize the potential of existing sea yet. Sea world could actually be a very strong branding material, but so far the discourse could not be realized due to the Annual General Meeting (AGM). From the expertise point of view, with the potential existing sea, WBL could brought branding with the slogan "The Miracle of Sea".

Brand's strength was determined by four components. Strong brands were marked by high functional and emotional benefits, and on the low cost and other expenses. Brand was a firm's equity that adds value to the products and at the same time to the investment offers. A strong brand gives visitors more confidence in the level and probability of a desirable return. A strong brand grants the firm some leverage over the perceived value of its investment.

"The Miracle of Sea" was a branding that had been highlight the prime WBL rides of the sea, i.e. The sea world. Thus the dominance of visitors 
could include other than children-ranged age. Tourists will also interest in the natural beauty, especially foreign tourists. The benefits of branding development include: easier identification of WBL for seize the interest of visitors; create unique associations and significance that distinguish the WBL fom other tourisms; become the sources of competitive advantage of WBL to built an unique image that had been formed in the hearts of visitors; and financial sources turnver for WBL, especially regard to future revenue.

\section{Comparison of Reality and Conceptual Model}

We found a complementary elaboration between the state of reality and the model of Strategic Place Triangle. The reality is empirical situation, while SPT is a viewpoint by system thinking to assess the real world in terms of the conceptual model.The analysis result that sea factor was the key differentiating factor that usable as a tool to establish a strong positioning and differentiation. Sea factor becomes a powerful tool because it derived from nature that could not be imitated by other tourism.

\section{CONCLUSION}

We concluded that the strategic planning of WBL did not completely accordance with the model of Strategic Place Triangle. The weak element on positioning and differentiation lead to the lack of development of brand. However, WBL has developed following details.

- WBL targeted all backgrounds and ages of visitors, yet to date the dominant visitors were children.

- The target market was in Java, especially Central Java and East Java.

- WBL has made the sea as their main differentiated factor thus named as marine tourism.

- WBL build their image by providing best service quality, security, comfort, cleanliness, and best quality rides.

\section{Recommendations}

For current conditions, segmentation of WBL should focus on children to increase the visitors. Segmentation can be improved for all backgrounds and age when there are new attractions such as Sea World. With sea world WBL market also could be expanded not only in Java, but also national.

WBL should emphasize the sea potential as authentic natural element that different to other tourism. WBL should not only provide best services to build a strong branding. WBL should also highlight the impression of the sea to provide a unique character in the WBL, e.g. The sea world, with the The Miracle of Sea slogan was proposed to be the brand.

\section{ACKNOWLEDGEMENTS}

The author regards to Suyanto as operational manager of WBL, Erdiana Renawati as the Head Department of Culture and Tourism in Lamongan, and Benny as HRD staff in WBL for his help in conducting the research.

\section{REFERENCES}

[1]. United Nations World Tourism Organization (UNWTO). 2011. Policy and practice for global tourism. Madrid, Spain, Calle Capitán Haya.

[2]. Regional Development Planning Agency (Bappeda). 2008. Preliminary Report: Evaluation and Revision Tourism Development Master Plan (RIPP) of Lamongan Regency. Lamongan Government, Regional Development Planning Agency.

[3]. Kartajaya, H. and Yuswohadi. 2005. Attracting tourists, traders, investors: marketing strategies in the regional autonomy era. Jakarta. Gramedia Pustaka Utama.

[4]. Kotler, P. 2004. Attracting investors: a marketing approach to finding funds for your business. Hoboken, New Jersey, John Wiley and Sons, Inc.

[5]. Wilson, B. 2001. Soft System Methodology. New York, USA, John Wiley \& Sons Ltd. 